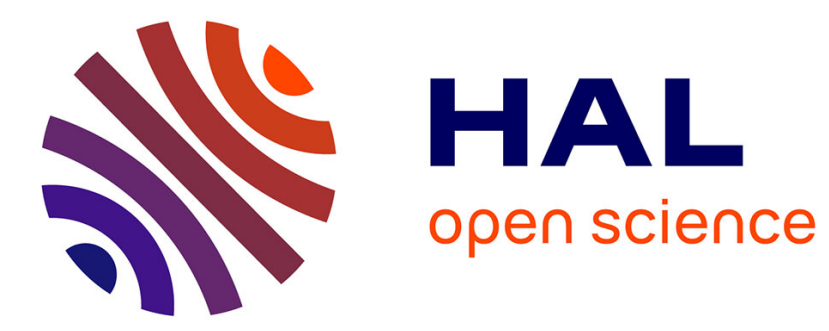

\title{
Exploring the Contribution of Design to Mobile Technology Uptake in a Remote Region of Australia
}

Fiona Brady, Laurel Evelyn Dyson

\section{To cite this version:}

Fiona Brady, Laurel Evelyn Dyson. Exploring the Contribution of Design to Mobile Technology Uptake in a Remote Region of Australia. 10th International Conference on Culture, Technology, and Communication (CATAC), Jun 2016, London, United Kingdom. pp.55-67, 10.1007/978-3-319-501093_4. hal-01619331

\author{
HAL Id: hal-01619331 \\ https://hal.inria.fr/hal-01619331
}

Submitted on 19 Oct 2017

HAL is a multi-disciplinary open access archive for the deposit and dissemination of scientific research documents, whether they are published or not. The documents may come from teaching and research institutions in France or abroad, or from public or private research centers.
L'archive ouverte pluridisciplinaire HAL, est destinée au dépôt et à la diffusion de documents scientifiques de niveau recherche, publiés ou non, émanant des établissements d'enseignement et de recherche français ou étrangers, des laboratoires publics ou privés. 


\title{
Exploring the Contribution of Design to Mobile Technology Uptake in a Remote Region of Australia
}

\author{
Fiona Brady ${ }^{1}$ and Laurel Evelyn Dyson ${ }^{2}$ \\ ${ }^{1}$ Bloomfield, Australia \\ Fbi_97@hotmail.com \\ ${ }^{2}$ University of Technology, Sydney, Australia \\ Laurel.E. Dyson@uts.edu.au
}

\begin{abstract}
Some of the most remote communities in Australia have participated in a technological revolution since the arrival of mobile phone networks in 2003. We follow this journey in four largely Indigenous communities in Cape York and the Torres Strait Islands, from the first $2 \mathrm{G}$ network, to 3G, and finally to mobile broadband and smartphones, looking at its impact on communication, Internet access, new media use and social networking. In seeking to understand this phenomenon, we conclude that aspects of the design of the mobile system have contributed, including the flexibility of the technology to adapt to the needs of varying social groups, the small portable nature of the devices which allows them to serve a traditionally mobile people and to be kept as personal devices, a billing system which serves low income people, and the multifunctionality of the technology which provide entertainment while also supporting their use of Facebook.
\end{abstract}

Keywords: mobile phones $\cdot$ mobile broadband $\cdot$ new media $\cdot$ social media $\cdot$ Indigenous people $\cdot$ Aboriginal people $\cdot$ mobile design

\section{Introduction: Problematizing ICT in Remote Australia}

Regions such as the Far North of Australia - Cape York Peninsula and the Torres Strait Islands which lie off its coast - have long posed a dilemma to Government telecommunications policy. Existing at the edge of the Australian continent, population density is low, the distances vast, there is little industry apart from the bauxite mines at Weipa, the weather can be extreme in the cyclone season, and the local rats have been known to gnaw through cable. There is therefore no business case for installing and maintaining telecommunications networks and the task of doing so is always a challenge.

However, the need for telecommunications in this region has been recognized for many decades. The earliest phone links to the townships scattered through the region came via radio telecommunications out of Thursday Island, the main centre in the Torres Strait. This was an open line so everybody could hear what everybody else said. In addition to this lack of privacy, there was a wait to get calls through, so communities like Kowanyama, on the end of the line, only used it in emergencies (Manager, Kowanyama Aboriginal Land \& Natural Resource Management Office, personal communication). When landlines arrived in the late 1980s, telecommunications improved enormously, but were still limited for the most part to services and businesses.

Only a very small minority of Indigenous households in the nine discreet Aboriginal communities in Cape York and those in the Torres Strait Islands subscribed to a home phone. There are many reasons for this documented in government reports, including factors of geography (prohibitive connection costs in remote areas and obstacles to maintenance when technicians have to travel long distances) and issues associated with the mismatch of the design of the telecommunications system with socio-economic circumstance and Indigenous culture (the individual focus of fixed-term billing contracts, the associated difficulty of a single subscriber paying potentially large bills for a home phone connection when cultural obligations make it hard to refuse access to family members, overcrowding in households, the unpredictability of post-paid bills, and the inability of the technology to support mobility of use) [DCITA, 2002; RTIRC, 2008].

Thus Indigenous residents depended mostly on the public telephone box when they wanted to make or receive a phone call. Later, when computers arrived on the scene, they used the free-access computers in the community technology centres. Computer training and use became part of school life, and also part of the workplace for those with jobs at the local Council or in service offices. (Adults lacking computer skills can still go to the Council Office and ask a clerk to perform tasks like Internet banking for them.) Sometimes special funding was allocated, for example through the libraries, for computer-based projects, but these rarely survived beyond the life of the project, despite being carefully designed to fit with presumed Indigenous cultural strengths. 
Real change came early in the twenty-first century. The Government noted in 2002 that some 200 Indigenous communities - from cities to remote regions - then enjoyed mobile coverage [DCITA, 2002]. Since that time Indigenous Australians have been shown to be willing adopters of what has been dubbed throughout the world the "mobile revolution ... this mobile miracle" [Sanou, 2013, p. 1]. In contrast to the public phone and public computers, this is the first information and communications technology (ICT) that most have personally owned.

This chapter presents a longitudinal perspective of how mobile technology has been taken up by Indigenous Australians in the Far North since our research into the phenomenon began in 2007. We present an overview of the evolving mobile narrative, providing interpretations from design and media studies. The four research sites are Dauan in the Torres Strait, and the Aboriginal communities of Lockart River, Wujal Wujal and Kowanyama in Cape York (see Figure 1). Their populations are respectively 150, 542, 305 and 1,200. Research was conducted by ethnographic observation; informal and semi-structured interviews and surveys with Indigenous and nonIndigenous residents; and technology assessments and measurements. Most recently we undertook readings of individuals' public Facebook pages from Wujal Wujal and interviewed managers there about this phenomenon. We take a systems design approach to technology, from personal devices, to infrastructure, mobile use, Government policy and billing structures, as well as competing ICT such as fixed-line and public phones and computers.

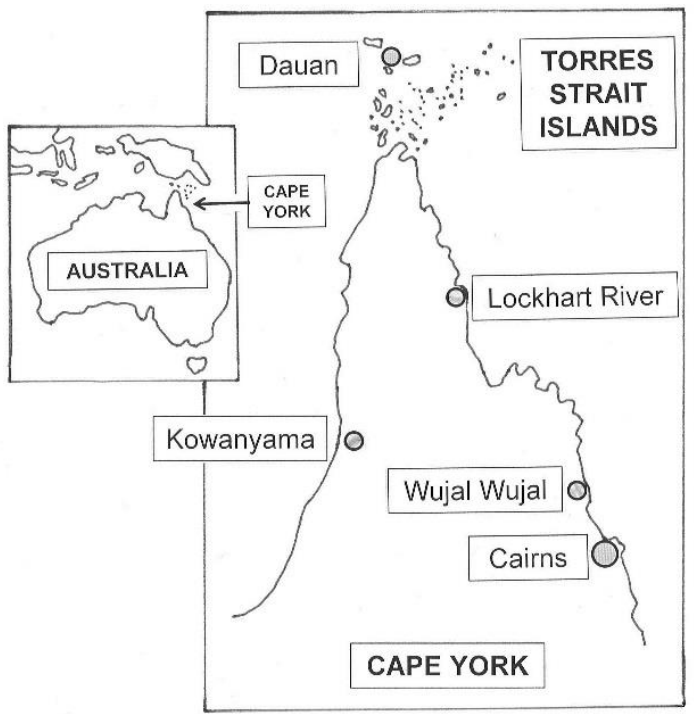

Fig. 1. The four research communities and main city of Cairns

\section{Moments of Translation in the Mobile Journey}

\subsection{Becoming Interested: The First Network}

A CDMA (Code Division Multiple Access) service rolled out across the Cape York communities in 2003 [Pearce, 2003], run by Telstra, the only provider in remote regions of Australia. The islands of the Torres Strait had to wait two years more [Brady, Dyson \& Asela, 2008]. Despite a general Federal Government mobile telecommunications policy in favour of competition (similar to other English-speaking countries like the USA and UK [Agar, 2003]), the pragmatics of remote location and a low population base gave the edge to the previous national telecommunications carrier, with its existing infrastructure.

This offered a voice call and text message (2G) service and was widely taken up by businesses and service providers, as well as by individuals. Many Torres Strait Islanders, for example, became aware of the mobile network even before it was available at home since they had family and friends on the mainland, or could pick up the signal if they lived on the inner islands close to the Australian continent. Most surprisingly, many people on the small outer island of Dauan had bought mobile phones even before their service was switched on, though they were then of no use whatsoever. Later, within a few short weeks of the coming of the mobile network in 2005, it was observed that most adults in the community had a phone [Brady, Dyson, \& Asela, 2008]. "Everyone I want to talk to has mobiles. Very hard to contact people otherwise," reported one young woman. 


\subsection{Enrolling in the 3G Network}

About June 2007 a 3G (third-generation) network was switched on. In January 2008 Telstra switched off the CDMA service, thus forcing anyone who wanted a mobile phone to buy a $3 \mathrm{G}$ phone. There was a common idea in the communities that "just about everyone has them" [Brady \& Dyson, 2009, p. 26]. In fact, our research in Wujal Wujal showed that not everybody owned a mobile - only $55 \%$ of the people we spoke to. Yet this was much higher than ownership of fixed-line phones or computers and therefore represented a major shift in technology access. Similar numbers have been reported in other remote communities by the Tangentyere Council and Central Land Council [2007] and Auld, Snyder and Henderson [2012]. The latter make the point that cultural norms of sharing mean that almost everyone has access to a mobile when they need it, although our research showed that sometimes people with mobiles avoided sharing with others they deemed unreliable.

As with the earlier service, so with the $3 \mathrm{G}$ phones, $100 \%$ of the people in Lockhart River and Wujal Wujal whom we spoke to who owned a mobile phone used them for communication - either phone calls or text messages or both - to family, friends, boyfriends, girlfriends, people in hospital, children away at boarding school or for work; to people at long distance or those who lived just around the corner. At Lockhart River a group of teenage girls texted each other "What's the plan?" to find out what was doing on the weekend, while a young mother rang the carer who was raising her daughter far away in the city of Cairns [Dyson \& Brady, 2009]. At Wujal Wujal a mother with children at boarding school had a phone so that "They can contact me. ... More for emergencies at school. ... I would like to be informed by the school about what's going on ... Pretty well talk to them every day", and an aged-care worker said "I need a phone for three clients ... I need a phone for clinic or the police ... I'm worried about my clients" [Brady \& Dyson, 2010]. One young man employed by the Council used it "for emergency. Calls - call family. Use it for work."

Sometimes the network did not deliver quite what was expected. Managers reported that the old CDMA service had better coverage: "When it works, it's pretty good. Bring me my analogue back. I had better coverage on that than on this digital thing." People complained they couldn't use their phones to make calls or send messages outside the area of the town or line of site of the tower. Coverage could best be described as patchy. At Wujal Wujal you couldn't contact the airport, the sports oval, the telephone exchange, most of the favourite fishing spots or people driving on many of the roads [Brady \& Dyson, 2009]. "I can't ring my Mum," said one woman, "She lives at Ayton," a village near Wujal Wujal. One man said that: "Sometimes I take mine in the bush but don't get enough signal." Another put an aerial on his car to increase the signal and even made calls at home from his car. However, with fixed-line phones in only 7\% of Wujal Wujal households [Cook Shire Council, 2008/2009], mobile was better than nothing - or better than going out in all weathers to the public phone booth, where everyone could see you and wonder who you were calling.

The great advantage of the new $3 \mathrm{G}$ service over the previous one was that it opened up the Internet and a host of new media to Indigenous people. The phones came with a camera, video camera, sound recorder, MP3 player, games, address book, calendar and alarm clock. Our study at Lockhart River was the first to discover just how much use people made of the new media features of their phones [Dyson \& Brady, 2009]. Often media came up first when young people listed their uses: "I Bluetooth [music], games, text message, ring." Many people listened to music: young people were seen walking around their community with earphones connected to a phone in their top pocket, young men sometimes listened while playing football, and people shared music from the local band. Mobiles provided the music for the Friday night disco at the Church Hall during school holidays: "Some of the kids plug their mobile phone into a speaker to play," reported one teenage boy. Playing games and watching movies, TV and sport on the Internet were all big. Communication was no longer confined to language through phone calls and text messages, but expanded to image through video calling and Bluetoothed photos and videos. User-generated content became important, sometimes working in with traditional cultural practices, such as when a young hunter videoed himself with his prey.

\subsection{Mobilizing over Time}

There has been no sign of the "mobilization" of Indigenous residents of these remote communities abating. For example, in Kowanyama the Post Office reported selling 40-50 mobile phones a month, while the Kowanyama Store sold 3-4 a day, when we were interviewing managers in 2014 [Brady \& Dyson, 2014]. One described the dependence of the residents on their mobiles, in the absence of landlines and home computers, as "vital ... Their only form of communication to the outside world is their mobile." Even $85-95 \%$ of high school children own mobiles, largely because the majority attend boarding school and this was the only way they could stay in touch with family back home. The Community Support Officer with the Education Department noted that, "It's absolutely vital for kids' well-being. The kids get distressed if they can't contact parents. Parents get distressed if they can't contact their kids."

A change in the style of mobile phones sold in the communities has been visible over the decade of our

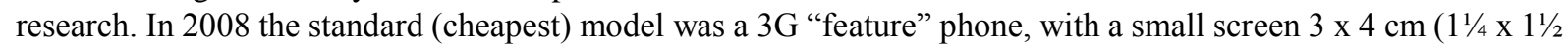


inches) and buttons for interaction. By 2014 only a handful of these were in the shops in Kowanyama and they were almost invisible in the community. Instead the standard had become the "flip" phone, once a luxury possessed only by the high-end users. Even more surprising were the touchscreen smartphones, most popular with young people. The cheapest touchscreen models were available for the same price as the flip phones, and almost a third less than the much more basic feature phone sold for in 2008 .

The move to smartphones suggests changing patterns of interaction. We had heard of Torres Strait Islanders using social networking sites like Bebo back in 2007, but at Kowanyama many young people were using Facebook, usually on their mobiles but also on the public access computers [Brady \& Dyson, 2014]. The offering of laptops and simple tablets for sale in the Post Office may also have been connected with social media, but it was impossible to gauge as we saw none in use publically.

In Wujal Wujal, in our most recent study, there was a perception by a number of people interviewed that everyone was on Facebook. An examination of the public Facebook pages of 10 Aboriginal people showed a great dependence on photographs, with only two having no images, and two using both photos and emoticons. Commensurate with this exploitation of the visual, very limited amounts of text were used, nearly always in nonstandard English, and often with abbreviations typical of text messages which indicated that they were probably using their mobile phones for "Facebooking". The photographs were nearly all of people - either of self or family - and women often had photos of their children, but not of partners. A few people had pictures from advertising of African American musicians or sports idols, and some had an image and message generated by a game they were playing. In a few photos, the person appeared against the backdrop of a local beauty spot. Some displayed photo editing as part of a local football promotion but, other than this, only one person obviously edited her photos to include decoration. The written posts included diary-like entries, for example, to say where they had arrived on a journey or what they were eating, or messages to family or friends, sometimes obviously living at some distance. One young woman posted images of her new baby, while another gave out a birthday wish. One used her Facebook post to memorialize her father, who had passed away, and this person was the only one to include religious content. In terms of specific Aboriginal content, only one featured images and news items of a political nature, namely, deaths in custody and domestic violence - both prominent Aboriginal concerns - while popular pastimes, such as camping, fishing and football, figured in some. Only one Facebook user stood out as having a predominance of beautiful photographs of scenery and an item of bush tucker in preference to images of people: he included lengthy explanations (up to 6 lines of text) in standard English describing what the photos represented.

Interviews with managers at Wujal Wujal revealed that they were all aware of Facebook, but most were only in the process of getting Facebook pages set up to augment their organizational websites. One exception was the Facebook site for the Indigenous Knowledge Centres (IKCs) of the State Library of Queensland: this had been launched and is maintained by the State Library but any IKC around the state can add or share content. For example, the Librarian of the Wujal Wujal IKC shared the link of the "Bloomfield River Oral Histories" and "it got out" to the community. Several issues surfaced as to why not more local organizations had put up a Facebook page. For the Manager of the Bana Yirriji Arts Centre, the unreliability and amount of downtime on the Internet was a problem: "The No. 1 issue is the Internet: you are waiting all day to do something and then have to do everything in an hour, all at once." Generally, there was a lack of time: both the Arts Centre Manager and the person in charge of the Wujal Wujal Aboriginal Shire Council website stated that they had been too busy. Technical issues also surfaced: finding out how to connect the Council website to Facebook was a problem. Decisions need to be made about how to control "inappropriate language", disrespect to the Council or Mayor, and pornographic content.

However, they recognized the value of Facebook. The ease of putting photos and other content up compared to populating the organizations' websites was a major advantage. Whereas the Arts Centre wanted to use it "Mainly for advertising", for example to post pictures of art works for sale at the Centre, notices of workshops they were running and "Go Back to Country" material, the Council realized that it would be a means "For getting the community involved. ... "We want to feel other people's opinion." This contrasted with the website which was solely for giving out information.

\subsection{Mobilizing Service Providers and Businesses}

Mobile broadband is a more recent player in the Far North communities, first observed in operation by the researchers in 2014 [Brady \& Dyson, 2014]. Anyone with a mobile broadband account and a dongle or wireless modem can link their computer or laptop to the Internet via the mobile network. In our research in Kowanyama we saw service providers and businesses using it to varying degrees.

The service providers were totally reliant on their mobile voice service for communication and the mobile broadband for Internet access. For example, Jobfind and the Remote Area Aboriginal and Torres Strait Islander Child Care depended on the mobile network and their mobile phones and laptops when their staff travelled to the community for work and so did not need to keep a permanent office fitted out with computers and landline phones 
in Kowanyama. The mobile phone allowed them to contact clients by SMS, who in turn could contact the service provider if they are were unable to get to an appointment. The slowing of the network at peak times, however, when everyone in the community was on their mobile phones, sometimes interfered with their ability to use their systems efficiently: "Speed is a real issue. ... If it was faster, I could actually get things done. It's been five minutes from one click to another," complained the Jobfind officer.

The small shops and cafés mostly had a mix of mobile and fixed-line. Only one shop had gone totally mobile, relying on mobile broadband for all stock orders, electronic funds transfer and email communication, except during cyclones when the systems were moved temporarily back to dial-up. Speeds at peak usage times, though, were again a problem, slowing "regularly at lunchtime, Friday evenings and on Saturdays and Sundays. As soon as they get off work or school, people get on their mobile phones and start text messaging and using Facebook." The slow speeds influenced three other small businesses to stick with landlines and dial-up connections for Internet access, keeping their mobile phones for calls and SMS. A couple of other businesses used mobile broadband for email, whereas the largest enterprises had robust systems based on landlines, ADSL, intranets, dedicated servers, satellite Internet connections or satellite phones. Their main use of mobile technology consisted of making calls on their mobile phones when away from the office.

Ironically, the very popularity of the mobile service was eating into its usability. The Acting CEO of the Council noted that: "More bandwidth is required. Both download and upload are very slow, even if you live right near the Water Tower [where the repeater was located]. It takes so long that you can make a cup of tea while it downloads. ... It's as slow as it was when we used to have dialup 10 years ago."

Therefore, the complete "mobilization" of businesses in these communities is yet to come, but may not be far away. Recently Kowanyama and the neighbouring community Pompuraaw joined forces to lay fibre optic cable from their mobile towers to the fibre optic spine that runs up the centre of Cape York. This first project of its type in these two communities should improve bandwidth and speed of service and encourage more businesses to go mobile in 2016. Rather than accept whatever the Government funds and negotiates with Telstra on their behalf, they have taken the lead in deciding their own mobile technology priorities and making it happen.

\section{The Design of the Mobile Service}

Kevin Warwick [in Jones \& Marsden 2006, p. 8] notes the difficulty of design in areas of technological innovation:

there's a big danger in focusing too much on what people think they want or need - sometimes, only when they experience a new technology can they articulate its value to them and help shape its development.

Different approaches to designing mobile technologies for Indigenous Australians have been adopted, with varying degrees of success. One very limited venture was the Gambara Gamu Biyu body chart, with which children could interact using a language pen to read off words for parts of the body in nine Queensland Indigenous languages [State Library of Queensland] - enough to hold the attention of children for a few minutes at most when it was put on display in the Bloomfield Library one school holidays in September 2012. The inclusion of more than one language on the resource meant that children were distracted from learning the local language KuKu Yalanji, and comments from parents indicated that it would be better placed in a school as part of a language program rather than the library, where it became more of a toy.

By contrast, is the highly successful Ara Irititja cultural database, which allows members of the Central Australian Pitjantjatjara community to view, annotate and add to an archive of images, video, sound recordings, etc., from a mobile niri-niri, that is, a type of complete workstation on wheels. The latter allows the database to be used wherever people are located, "easily moved from community halls to classrooms to bush camps to dry creek beds", or loaded onto the four-wheel drive vehicles used for longer trips [Hughes \& Dallwitz, 2007, p. 154]. The challenge of designing and implementing this system - database, interface, protocols of use, mobile hardware can be gauged from the fact that it took 2,000 hours and over ten years to develop: this allowed the local people to understand the system thoroughly, to review the development process at their own pace and to build a sense of ownership, resulting in its integration into the lives of the people.

Unlike Ara Irititja and some rock-bottom phones and phone cards developed by mobile providers in Africa for poor people to use (e.g., Orange in Morocco), the mobile phones, MP3 players and tablets that Indigenous Australians have are mainstream. We presume that neither the original nor subsequent designers of mobile technology considered the inhabitants of remote Australia in their design decisions. Reading Jon Agar's [2003] history of the mobile phone we note contributions to its development from several regions of the world, particularly the USA, Japan, the Nordic countries, the UK and other parts of Europe. Some of these contributions, like the advances in miniaturization which led to smaller phones that were light enough to carry around, and the 
development of modern billing structures (pre-paid charging and phones sold cheaply but whose price is then subsidized by airtime) added to the attractiveness of the mobile phone for Indigenous Australians, despite not being designed specifically for them.

Here we consider some of the major characteristics of the design of the technology which our research indicates have made mobile technology attractive to Indigenous people.

\subsection{Flexibility}

Flexibility must certainly be a characteristic of a technology which straddles culturally and socio-economically diverse groups of people and geographically diverse regions. One of the authors, in an early consideration of Indigenous Australians and ICT, noted that ICT is an inclusive medium, which allows Indigenous users to achieve their own goals: she proposed that it does this through aspects of its design, including lack of traditional hierarchies, absence of prejudice, its interactivity and flexibility, and its breakout of the visual (Dyson, 2003). In terms of mobile technology, we would now add to this list the breakout of the oral and aural.

Many years ago Doris Schoenoff (1993, p. 76) recorded the adaptability and multipurpose nature of computers, which can be applied just as well to mobile phones, the mini-computers of our age:

... a unique tool because its purpose is constantly being reinvented by its users. Its power consists in the fact that it is a symbol machine, and its symbols and their interpretations can be altered.

More recently Inge Kral [2012, 245-6], in a study of the Ngaanyatjarra people of the Australian desert, drew attention to the "spatially-oriented and icon-based structure" of ICT, and how the "logic of the symbol system ... the symbolic conventions" have supported young people to become "fearless of technology". Even Indigenous youth with limited literacy skills can move through the necessary interactions with the technology, supported by "standardized alphabetic symbols, left-to-right and top-to-bottom processing interacting with a pictographic symbol system ... using icon-based navigation" [Kral, 2012, p. 249] Even in the early days of mobile phone adoption people were "extremely capable" at using their mobile phones, according to the Wujal Wujal Post Mistress, "If they don't know, they get their family to help them." Thus any deficiencies in design which made some unable to carry out the more complicated functions on their phones, could be made up for by the social system. Generally there was an impression by older people about the young that, "They know more".

\subsection{Portable and Personal}

The most obvious characteristic of mobile technology is its small size, lightness and hence portability. This design feature supports the communications needs of previously non-sedentary people to renew for at least some times of the year their culture of temporary mobility or "walkabout" - visiting family in other communities, going camping, fishing or hunting, and escaping from the administrative aggregations of population that still echo the mission days, with their fixed services of housing, health, education and fixed communications.

The portability of the devices means that they have become personal devices, too, small enough to be kept in a pocket or hung around the neck. They allow some measure of privacy in phone conversations - permitting people living in overcrowded housing to take a call outside, without everyone listening in - and a whole world of private music listening: one mother, talking of her music preferences, stated, "For your ears only' - if the kids don't like it a lot they'll tell you." Importantly, the portability and small size allow owners of mobile phones some measure of control over the devices, to decide if they will share them and whom they will share them with. One woman, whose nieces and nephews swap the battery and take the SIM card out, recorded that, "Have to keep it on me. My Mum doesn't trust them with her phone - steals her credit." Inge Kral [2012, 230] notes that "In an environment predicated upon demand sharing, these are items of personal ownership that don't have to be shared."

\subsection{Billing Structures and Cost Management Features}

Incomes in the communities are generally low compared to the national average, with high levels of welfare dependency and most people 'living right up to the limit' of their income, as one manager told us. The cost management features offered by mobiles are therefore one of the major reasons for their success compared to landlines.

A feature of the design of the mobile service is pre-paid billing. Some of our interviewees in Lockhart River and Wujal Wujal recounted horror stories of bills in the thousands of dollars that they or others had incurred when buying non-pre-paids when visiting phone shops in town or in the early days of the mobile service when CDMA was in place. Recent interviews with managers at Wujal Wujal revealed that the Indigenous Consumer Assistance Network in Cairns worked with the communities to arrive at a solution when the problem first arose: since the 
local council owned the shop which sold mobiles, they could control what phones and services were for sale. For a long time now all shops in the four communities have sold nothing but pre-paid mobile phones, and more recently pre-paid dongles for home access to mobile broadband from laptops.

Other features which help keep costs low are the use of text messages instead of calls, the low cost of the most basic 3G mobile phones sold in the community shops, no connection fee compared to landlines, and the disposability of phones compared to landlines and computers, which need a technician to fly or drive in usually from a considerable distance to fix them when they malfunction since there are no technicians living in the communities.

MP3 players or iPods are another well-designed mobile technology which has persisted over time because listening to music is extremely popular in all the communities and the devices are cheap to buy: in 2014 the Kowanyama Post Office was still selling about 20 players per month, some for as little as \$20 [Brady \& Dyson, 2014], despite the fact that many use their phones to listen to music instead. One advantage of MP3 players is that they avoid the recurring costs of mobile phone charges, particularly for children and for adults on low incomes.

\subsection{Multifunctionality and Social Networking}

The multifunctional design of the $3 \mathrm{G}$ phones that were introduced to the Indigenous communities of the Far North in 2007/08 must also be ranked as an outstanding factor in their adoption. The high level of interest in mobile media is not surprising given the traditional cultural strengths of Indigenous Australians, namely in oral and audio practices (song, music, story-telling and ceremony) and in pictorial expression (painting, sculpture, carving and weaving). Further, new media functions have the advantage that they are always usable, even when the network is down or the owner has run out of credit, a common occurrence in these communities [Auld, Snyder \& Henderson, 2012]. Mobile technology thus can play a significant role in personal wellbeing in remote communities with limited amusement options. Mobile technology has joined TV, radio and CD players in serving that essential part of the human spirit - our endless love of music and storytelling.

Mobile phones allow the taking of photos and video which, combined with instantaneous upload to the Internet, has facilitated the explosion of participation in social media. Bronwyn Carlson [2013] notes that Facebook is now an everyday activity for many Indigenous people, and our observations in Kowanyama and anecdotal evidence from Wujal Wujal would appear to support this. The design of Facebook, which makes upload of images simple and allows people to participate without requiring a large amount of textual input, is key. Even responses to posts can be non-textual, for example, a show of emotion through "likes" and emoticons.

Facebook is about communication, but also enables people in these communities to actively and purposefully "build, display, and perform Aboriginal identities", as noted by Carlson [2013, p. 147]. We saw on the public Facebook pages of Wujal Wujal residents how this was effected by using images of self, family, friends and local places, as well as comments in a style of non-standard English which appeared to identify them as Aboriginal people [Carlson, 2013]. Manuel Castells interprets such online manifestations as part of the "constitution of new forms of individual and collective identity", in which identity is seen as "people's source of meaning and experience ... the process of construction of meaning on the basis of a cultural attribute, or a related set of cultural attributes, that is given priority over other sources of meaning." [Castells, 2010, pp. xviii, 6] Such affirmations of identity become a "fundamental lever of social change" [2010, p. xvii].

Johnny Winston [2013] comments that photos are increasingly used to communicate, construct identity and understand reality on Facebook. Photos are a shortcut for disseminating one's experiences with large numbers of people quickly and easily and are valued because they are seen to provide information and appear to be trustworthy in that they show evidence that an event occurred. In fact, photos predominated on the Facebook pages we viewed. However, depending on photographs for information is dangerous since they can be subtly manipulated in the process of selection. In addition, Winston [2013, p. 3] argues that they are "more ambiguous than written descriptions because they show rather than tell"; they neither connote a fixed idea nor denote explicitly, and so can result in "miscommunication or unintended interpretation of communication when it is used to carry information."

Castells suggests that for a given individual or collective there may be multiple identities and that this is "not a source of weakness but of strength in a society characterized by flexible networks and variable alliances in the dynamics of social conflicts and power struggles." [Castell, 2013, p.258] So while Facebook has become a popular and powerful social medium it must be "read" in the context of this new medium itself - its flexibility, its ability to create fluid identities, and to convey information, even if at times biased.

\section{Conclusion}

Matt Jones and Gary Marsden, in their book on Mobile Interaction Design [2006], note that people: 
will not take up a technology unless there is a very good reason to do so. A new mobile product will click with people if it allows them to achieve something significant while fitting in with the other things that fill their lives. On top of these two critical success factors, products should also be pleasing, charming, delightful and enjoyable, rather than annoying, bland, frustrating and dull.

From the ready take-up of mobile technology by the Indigenous communities of the Far North, it can be seen that it has fulfilled needs that were not answered by the previous generation of fixed-line ICTs - the need for a tool for communication, a medium for exploring identity, and a multifunction device which can play music or games, access TV programs or sport, in short to pass the time enjoyably. The design of the technology - its flexibility, portability, personal nature, cost management features, multifunctionality and affordance for social networking - has contributed significantly to making the mobile phone and MP3 player (and increasingly tablets, laptops and mobile broadband) technologies of choice for these communities.

Acknowledgements. We would like to thank the people of Dauan, Wujal Wujal, Lockhart River and Kowanyama who have shared their experiences and thoughts about mobile technology with us over the years. We further thank the mayors, councillors and managers of the four communities who facilitated our research.

\section{References}

1. DCITA (Department of Communications, Information Technology and the Arts): Telecommunications Action Plan for Remote Indigenous Communities: Report on the Strategic Study for Improving Telecommunications in Remote Indigenous Communities (TAPRIC), Commonwealth of Australia. (2002)

2. RTIRC (Regional Telecommunications Independent Review Committee): Framework for the Future: Regional Telecommunications Review. Commonwealth of Australia, Canberra (2008)

3. Sanou, B.: Preface. In: The World in 2013: ICT Facts and Figures. International Telecommunication Union (ITU) (2013)

4. Pearce, J.: UPDATE: Qld government muscles carriers into better coverage. Zdnet. (2003, July 7).

5. Brady, F., Dyson, L.E., Asela, T.: Indigenous Adoption of Mobile Phones and Oral Culture. In: 6th International Conference on Cultural Attitudes towards Technology and Communication (CATaC), pp. 384-398. Nîmes, France (2008)

6. Agar, J.: Constant Touch: A Global History of the Mobile Phone. Icon Books, Duxford, UK (2003)

7. Brady, F., Dyson, L.E.: Report to Wujal Wujal Aboriginal Shire Council on Mobile Technology in the Bloomfield River Valley. Wujal Wujal Aboriginal Shire Council, Wujal Wujal (2009)

8. Auld, G., Snyder, I., Henderson, M.: Using Mobile Phones as Placed Resources for Literacy Learning in a Remote Indigenous Community in Australia. Language Learning and Education, 26, 279-296 (2012)

9. Dyson, L.E., Brady, F.: Mobile Phone Adoption and Use in Lockhart River Aboriginal Community. 8th IEEE International Conference on Mobile Business, pp. 170-175 (2009).

10. Brady, F., Dyson, L.E.: A Comparative Study of Mobile Technology in Remote Australia. In: 7th International Conference on Cultural Attitudes towards Technology and Communication (CATaC), pp. 69-83. Vancouver, Canada (2010)

11. Cook Shire Council. Cooktown \& District Telephone Directory 2008/2009: Cook Shire Council. (2008/2009)

12. Brady, F., Dyson, L.E.: Enrolling Mobiles at Kowanyama: Upping the ANT in a Remote Aboriginal Community. In: 9th International Conference on Culture Technology Communication (CaTaC), pp. 179-194. Oslo (2014)

13. Jones, M., Marsden, G.: Mobile Interaction Design, John Wiley \& Sons, Chichester, UK (2006)

14. State Library of Queensland: Bodychart Wordlists - Gambara Gamu Biyu, http://www.slq.qld.gov.au/resources/atsi/languages/resources

15. Hughes, M., Dallwitz, J.: Ara Irititja: Towards a Culturally Appropriate IT Best Practice for Remote Indigenous Australia. In: Dyson, L.E., Hendriks, M., Grant, S. (eds.) Information Technology and Indigenous People, pp. 146-58. Information Science Publishing, Hershey, USA (2007)

16. Dyson, L.E.: Indigenous Australians in the Information Age: Exploring Issues of Neutrality in Information Technology. In: 11th European Conference on Information Systems (ECIS), pp. 1-12 (2003)

17. Schoenhoff, D.: The Barefoot Expert: The Interface of Computerized Knowledge Systems and Indigenous Knowledge Systems. Greenwood Press, Connecticut. (1993)

18. Kral, I.: Talk, Text and Technology: Literacy and Social Practice in a Remote Indigenous Community. Multilingual Matters, Bristol (2012)

19. Carlson, B.: The "New Frontier": Emergent Indigenous Identities and Social Media. In: Harris, M., Nakata, M., Carlson, B. (eds.) The Politics of Identity: Emerging Indigineity, pp. 147-68. University of Technology, Sydney (2013)

20. Castells, M.: The Power of Identity, $2^{\text {nd }}$ ed. Wiley-Blackwell, Chichester, UK (2010)

21. Winston, J.: Photography in the Age of Facebook. In: Intersect, 6, 1-11 (2013) 